\title{
Testing the tunnel effect: comparison, age and happiness in UK and German panels
}

\author{
Felix R FitzRoy ${ }^{1}$, Michael A Nolan ${ }^{2}$, Max F Steinhardt ${ }^{3 *}$ and David Ulph ${ }^{1,4}$
}

\author{
* Correspondence: \\ steinhardt@hsu-hh.de \\ ${ }^{3}$ Helmut Schmidt University, \\ Holstenhofweg 85, 22043 Hamburg, \\ Germany \\ Full list of author information is \\ available at the end of the article
}

\begin{abstract}
In contrast to previous results combining all ages, we find positive effects of comparison income on happiness for the under $45 \mathrm{~s}$ and negative effects for those over 45. In the UK, these coefficients are several times the magnitude of own income effects. In West Germany, they cancel out to give no effect of comparison income on life satisfaction in the whole sample when controlling for fixed effects, time-in-panel, and age-groupings. Pooled OLS estimation gives the usual negative comparison effect in the whole sample for both West Germany and the UK. The residual age-happiness relationship is hump-shaped in all three countries. Results are consistent with a simple life cycle model of relative income under uncertainty. Jel codes: D10, 131, J10

Keywords: Subjective life-satisfaction; Comparison income; Reference groups; Age; Welfare
\end{abstract}

\section{Introduction}

Among the most important results in happiness research, which help to explain the Easterlin Paradox of flat or declining average life satisfaction over time in the US and other advanced economies, are the strong negative effects of comparison with peergroup income found in many different contexts, but particularly for life satisfaction in Germany and the US. ${ }^{1}$ However, as Hirschman and Rothschild (1973) observed, just before the seminal paper on subjective well-being by Easterlin (1974), comparison with a relevant reference group could have two very different effects. First, the role of status based on comparison, which had already been emphasised by classical economists such as Smith and Mill and by Veblen (1899), and more recently by sociologists as 'relative deprivation' (Runciman 1966), refers to evaluation of one's own current situation compared to the relevant reference group. However, Hirschman and Rothschild (1973) argued that in the context of economic development and resulting inequality combined with rapid growth, comparison could also indicate one's own future prospects. Thus a higher peer-group income in this context might be perceived as only a temporary setback, but also as an indicator of better future prospects for more rapid advancement to catch up with peers, which they denoted 'the tunnel effect', with an inherently ambiguous net result on current subjective well-being.

While such effects in developing countries are plausible, there is also a natural asymmetry in likely response to relative income across age groups, which has received much less attention. Young individuals everywhere are obviously more mobile and likely to

(C) 2014 FitzRoy et al.; licensee Springer. This is an Open Access article distributed under the terms of the Creative Commons Attribution License (http://creativecommons.org/licenses/by/4.0), which permits unrestricted use, distribution, and reproduction in any medium, provided the original work is properly credited. 
see peer success as an indication of their own future prospects (and perhaps be motivated towards a greater effort to catch up) than less flexible, older people. The careers of the latter group are fully determined at the latest by retirement, so expectations lose relevance and current perceptions of relative status should dominate.

This plausible asymmetry suggests it may be wise to estimate the effects of relative income separately for younger and older sub-samples. So here we generalise earlier cross sectional results, which reported the first estimates for different age groups ${ }^{2}$, and use the German Socio-Economic Panel (SOEP) and the British Household Panel Survey (BHPS) to estimate life-satisfaction separately for sub-samples of individuals under and over 45 as well as for the complete samples with all ages. We control for the time spent in the panels and for age with age-group dummies and find a number of new results which differ from the previous literature.

In a first step, we estimate a pooled OLS model and find a negative comparison effect for the whole sample in West Germany, which is in line with the previous literature. However, the story changes if we run separate regressions by age groups. For individuals younger than 45 , we find a positive significant effect of comparison income, while the effect for the older group is negative. This confirms our previous cross-section results (FitzRoy et al. 2011a, 2011b). Second, we run estimations with individual fixed effects to take into account unobserved heterogeneity (Frijters and Beatton, 2012). Here we do not find any significant effect of comparison income in the full SOEP sample. Most importantly, we again find a positive significant effect of comparison income for those under 45 as well as the usual negative significant effect for the older group in West Germany. Comparison and own income coefficients have similar magnitudes, as in the US (Layard et al., 2010). Thirdly, interacting age intervals with reference income yields a similar declining - from positive to negative - effect on happiness with age. This is in keeping with the findings of Akay and Martinsson (2012), who combine East and West German data (and report similar effects from an experimental survey in Sweden). For East Germany, we find that comparison income effects for the complete sample and the sub-samples are close to zero, and other coefficients also differ.

We also obtain similar positive and negative comparison income results for the two age groups in the UK (using the BHPS), which appear to be new. Here the comparison effect is negative for the complete sample, both for pooled OLS and for fixed effects. Comparison income interaction with age intervals generates a similar - albeit less clearly defined - pattern to West Germany. We find comparison effects for both age groups to be several times larger than very small (though highly significant) ownincome effects in the UK. Already small, own income effects decline with age in the UK, in contrast to both German regions.

Thus fundamental results of happiness research change dramatically after disaggregating by age: the seemingly robust negative effect of reference income turns positive in younger sub-samples in West Germany and the UK (a result which is consistent with Hirschman and Rothschild's (1973) pioneering analysis, though not directly predicted by them) but remains strongly negative for older individuals. Moreover, comparison income has no effect in the full sample in both parts of Germany (and is actually insignificant in both age groups with fixed effects in East Germany).

We have also formalised some ideas about the links between age, comparison income and life satisfaction in a simple 2-period, life-cycle model with uncertainty (see 
Appendix A3). Depending on parameters, some members of the younger cohort may find that currently higher comparison income can signal either higher or lower expected lifetime relative income and, hence, expected life satisfaction. In the second period, realised relative incomes have the usual effect. This is not a general model of relative income since we do not consider optimizing responses to information and other issues and focus on exogenous shocks to the labour market. Also, it does not predict all our results, but it does capture one novel result of the empirical analysis, namely the possibly positive (signalling) effect of higher comparison income on some members of a young cohort's expected well-being, an effect which is lost under the usual aggregation of age groups.

The plan of the paper is to provide a brief review of other tests of the signalling or tunnel hypothesis in Section 2. In Section 3 we discuss the econometric specification and present empirical results for Germany and the UK. We discuss robustness tests in Section 4. The paper ends with policy conclusions in Section 5. The life-cycle model is in the Appendix.

\section{Other tests of the tunnel hypothesis and related literature}

Hirschman and Rothschild's (1973) ideas were long neglected, and most of the earlier empirical literature does not directly address the tunnel hypothesis but emphasised the negative effects of comparison. Thus in an early study with UK data for employees, Clark and Oswald (1996) found a strong negative effect of reference income on jobsatisfaction (which is generally an important component of life-satisfaction), equal in magnitude and opposite in sign to the own-income effect.

Earlier tests of the tunnel effect have produced conflicting results. For example, Drichoutis et al. (2010) found insignificant effects of comparison income for the transition economies of Eastern Europe, in contrast to Senik (2004, 2008), who obtained positive effects of reference income on life-satisfaction or financial satisfaction for most transition economies and Russia. She ascribed this contrast with 'old' Europe, with mainly negative effects of reference income, to social and economic turmoil after transition and consequent high mobility ${ }^{4}$.

A different kind of test of the signalling effect of comparison income has been carried out by Clark et al. (2009), using Danish establishment wage data. They concluded that job-satisfaction is higher in establishments with higher average pay, which plausibly signals one's own prospects for promotion in the future. Interestingly, in light of our findings below and our life-cycle model, they found less effect for those near retirement. However, it is also likely that higher average pay will be correlated with workplace public goods as part of rent-sharing with workers, which may explain part of the observed influence.

D'Ambrosio and Frick (2012) used an alternative approach to distinguish the status (or positional) relative deprivation effect of comparison income from the signalling (or tunnel) effect by adding lagged income in a dynamic context. They found negative status effects of income-distance from richer individuals and the converse for incomedistance from poorer people. They also interpreted a negative effect of comparison with people who are currently poorer but were richer in the previous period as a signal of possible loss of own future status. The importance of signalling thus also emerges in a very different context from our age-related, peer group comparison. Senik (2009) also 
considered dynamics and compared various reference incomes for transition countries, including past own income. She found stronger negative effects of relative decline than positive effects of relative gain, thus confirming loss aversion in this context. Another extension of the standard income comparison, due to Cuesta and Budria (2012) and Bellani and D'Ambrosio (2010), included relative deprivation measures in various nonmonetary, social and consumption domains, which turned out to be independently important for well-being. However these factors are all likely to be highly correlated with income, so it is not clear what additional insight these comparisons provide.

There is also evidence for the importance of comparison in general from neuroscience (Fliessbach et al., 2007) and from much work in psychology and behavioural economics, as reviewed by Clark et al. (2009).

A main finding is that much happiness-enhancing behaviour and disposition is already imparted in early childhood (Headey et al., 2012). People with these early advantages go on to be healthier and more successful in careers and personal relationships, all of which are themselves major contributors to later well-being (Frijters and Beatton, 2012; Layard et al., 2013). This underlines the necessity to control for position in the life-cycle and to account for individual unobserved heterogeneity when analysing the impact of reference income on happiness.

\section{Empirical analysis}

Our dependent variable is an individual's self-reported life-satisfaction. Our main explanatory variables of interest are own income and comparison income, which are both expressed in real terms and measured at the household level. ${ }^{5}$ Instead of the usual quadratic in age, we use age dummies for 10-year intervals. While a number of the many different ways of defining comparison income in the literature are discussed in the next paragraph, they are generally based on the idea that an individual compares his/her own income with the average income of people who form a peer group of 'similar' individuals. To obtain sufficient observations in a plausible comparison group, we choose individuals in an appropriate age 'range', living in the same region, in the same year $^{6}$, with the same gender and similar education. With respect to age, we use rolling 10-year age intervals, assuming that an individual at a particular date compares with peers up to 3 years younger and 6 years older $(-3 /+6)$. This asymmetry in the age range of the peer groups seems to be new: it is based on the idea that individuals will look to similar people, with somewhat more weight attached to those further on in their career, to form plausible expectations and aspirations about their own future relative income. Symmetric age ranges yielded almost identical results (see Section 4). However, purely forward-looking comparison for young workers on career paths with rising incomes would not offer clear signals of current or expected relative position but would simply indicate generally positive prospects in accord with natural career progression and rising incomes.

Blanchflower and Oswald (2004) and Luttmer (2005) do not use an explicit age dimension for their definitions of relative income, although they do include a spatial dimension. By contrast, Ferrer-i-Carbonell (2005) utilises fixed 10-year age brackets, and Layard et al. (2010) matches on age - but on a symmetric \pm 5 years basis, omitting a regional component. Pfaff (2013) compares estimates of comparison income effects with the last two definitions above and another variant by McBride (2001) for East and West Germany and the UK. He examines the restriction of coverage to working individuals and the impact of 
using different measures of income and finds that results are sensitive to the definition of both dimensions. However, he does not disaggregate any country sample by age. To justify our definition of comparison income, which is similar to Layard et al. (2010) but with a regional restriction, we conducted extensive robustness tests by varying comparison parameters and found our results to be quite insensitive both to comparison groups and specification changes discussed in detail in Section 4.

Many happiness studies (including some of the work on relative income cited above) control for age with a quadratic and find a robust U-shaped pure age effect (Blanchflower and Oswald, 2008). However, this does not capture the declining happiness of the oldest respondents, as is evident in samples with all ages where either cubic or non-parametric age controls are used (Fischer, 2009; FitzRoy et al. 2011a, 2011b; Bartolini et al., 2012, Wunder et al., 2013). Pfaff (2013) uses a quadratic in age and finds negative estimates for age squared until the sample is restricted to workers only, with the estimates then being positive for all three countries. With fixed effects and controls for time in panel and survey interview (but no comparison income), Frijters and Beatton (2012) and Kassenboehmer and Haisken-DeNew (2012) show that the U-shape or middle-age decline in happiness disappears. When we include comparison income as well as age-intervals, wave dummies, time in panel, and individual fixed effects, we find a hump-shape (with only a moderate decline in happiness after 75) in West Germany and the UK. Only East Germany reveals a substantial dip in middle age, and a deeper fall after 75 . These results are illustrated in Figure 1.

To test our main hypothesis about the varying influence of comparison income on life-satisfaction, we estimate the following model for the full sample as well as for two age groups, $<45$ and $>=45$ :

$$
H_{i t}=\beta_{0}+\beta_{1} \ln Y_{i t}+\beta_{2} \ln \bar{Y}_{j t}+\alpha X_{i t}+\gamma g\left(A g e_{i t}\right)+\varepsilon_{i t},
$$

where $H$ measures self-reported life-satisfaction of individual $i$ at time $t$, and $X$ is a vector of individual covariates including individual characteristics like gender, education, employment status, self-reported health and time spent in the panel, as well as dummies for regions. $Y$ captures annual household income of an individual, while $\bar{Y}$ describes the mean income of the corresponding reference group $j$ defined by age, gender, education and region. With respect to age, we follow Frijters and Beatton (2012) and use a relatively flexible function: we include age-dummies for bands of 10 years. Our reference category are those respondents younger than 25. Motivated by large and persisting socio-economic and cultural differences between West and East Germany (Frijters et al. 2004, Pfaff and Hirata, 2011), we estimate the same model for East and West Germany separately.

We treat life-satisfaction scores as cardinal and comparable across respondents. This assumption is sometimes criticised in the economic literature, but unreported estimates from a random effects, ordered probit model are qualitatively similar to the ones reported here. This is in line with the findings of Ferrer-i-Carbonell and Frijters (2004), so we proceed with pooled OLS and fixed effects estimates as in Layard et al. (2010) and others. In addition to separate age-groups, $<45$ and $>=45$, we also report estimates of an interacted model with the full sample. The age split was chosen in accord with standard labour force statistics to divide the extended 'prime age' working life from 25 to 65 , but dividing at 40 or 50 gave very similar results (see Section 4). 


\subsection{Data and results for West and East Germany}

The data used for Germany comes from the German Socio-Economic Panel (SOEP), which is a representative micro data set providing detailed information on individuals, families and households in Germany (Wagner et al. 2007). The SOEP was started in 1984 and has become a widely used database for social scientists. A major advantage is the comprehensive nature of the data set, which combines objective indicators (e.g. income, employment status, family structure) as well as subjective or self-assessed life-satisfaction. In this paper, we only use the 2000-2010 waves of the SOEP, in order to avoid the potential effects of reunification and its aftermath in earlier years, split into subsamples of individuals under 45 and those older than (or exactly) 45. We have over 156,000 observations for 26,711 individuals in West Germany and do not constrain ages as do Layard et al. (2010) ${ }^{7}$.

Self-reported life-satisfaction is measured on an 11-point scale, 0 being the lowest value, while 10 is reported by individuals who are very satisfied with their actual life. Household income is measured after deducting taxes and social insurance contributions. We define an individual's comparison group by gender, age $(+6 /-3)$, education (low, medium and high), time (year) and region (North, West, South-West, South). In the case of East Germany, we distinguish between two regions (North and South) ${ }^{8}$.

Tables 1 and 2 show brief summary statistics for West and East Germany. East Germans have lower average life satisfaction than West Germans with more unemployment and significantly lower household income than West Germans. The differences in happiness and economic outcomes between West and East Germany hold true when we compare people within age groups. However, the average life-satisfaction score in East Germany is still about 6.55, which is fairly high compared to self-reported happiness in the US (Layard et al. 2010). The table further shows that young adults in East and West Germany have higher life satisfaction than older individuals.

Table 1 Summary statistics, West Germany, 2000-2010

\begin{tabular}{|c|c|c|c|}
\hline & (1) & (2) & (3) \\
\hline & All & $<45$ & $>=45$ \\
\hline Life-Satisfaction & $7.14(1.74)$ & $7.22(1.65)$ & $7.08(1.80)$ \\
\hline Age & $48.30(17.15)$ & $32.67(7.77)$ & $61.11(11.02)$ \\
\hline Household income & $2872(1863)$ & $2872.13(1656)$ & $2871.41(2017)$ \\
\hline Comparison income & 2871 (799) & $2903.16(555)$ & 2845.07 (953) \\
\hline$N$ & 156194 & 70355 & 85839 \\
\hline
\end{tabular}

Table 2 Summary statistics, East Germany, 2000-2010

\begin{tabular}{cccc}
\hline & $\mathbf{( 1 )}$ & $\mathbf{( 2 )}$ & $\mathbf{( 3 )}$ \\
& All & $<\mathbf{4 5}$ & $>\mathbf{4 5}$ \\
\hline Life-Satisfaction & $6.55(1.78)$ & $6.73(1.69)$ & $6.42(1.82)$ \\
Age & $48.74(17.25)$ & $31.82(8.05)$ & $60.86(10.61)$ \\
Household income & $2248(1294)$ & $2349(1252)$ & $2176(1319)$ \\
Comparison income & $2240(562)$ & $2361.11(443)$ & $2152.82(619)$ \\
$N$ & 56456 & 23562 & 32894 \\
\hline
\end{tabular}

See Table 1. Comparison income measures the average net monthly real income within a reference group (Age $(-3 /+6)$, Sex, Education (3 categories), Regions (2 categories)) to which the respondent belongs. Source: SOEP. 
Tables 3 and 4 report pooled OLS estimates for the whole sample and the two age groups for both regions, restricted to the key household and comparison income variables. For own income in the full West German sample (column (1)), we find the usual positive effect. The corresponding coefficient has a value of 0.53 which is the typical size in a cross-sectional regression of life-satisfaction on log income (Layard et al. 2010). The negative comparison effect also matches previous work discussed in the Introduction. The magnitude of both income effects is very moderate. A $50 \%$ increase in own income is associated with an increase in life satisfaction of approximately $3 \%$, while an increase in peer income decreases predicted life satisfaction by roughly $0.5 \%$. The main interest comes from the age-split. The results in column (2) highlight that comparison income has a positive significant effect for individuals under 45, while maintaining the well-known negative effect for older individuals. These findings are in line with our earlier cross-sectional results focusing on the 2008-wave of the SOEP (FitzRoy et al. 2011a, 2011b).

Table 3 West Germany, SOEP, 2000-2010

\begin{tabular}{cccc}
\hline & $\mathbf{( 1 )}$ & $\mathbf{( 2 )}$ & $\mathbf{( 3 )}$ \\
& All & $<\mathbf{4 5}$ & $\mathbf{4}$ \\
\hline Pooled OLS & & & \\
Household income & $0.53^{* * *}$ & $0.43^{* * *}$ & $0.61^{* * *}$ \\
Comparison income & $(51.00)$ & $(27.81)$ & $(42.85)$ \\
& $-0.09^{* * *}$ & $0.18^{* * *}$ & $-0.19^{* * *}$ \\
Observations & $(-3.47)$ & $(3.86)$ & $(-5.77)$ \\
Adj. R-squared & 156,194 & 70,355 & 85,839 \\
\hline
\end{tabular}

Dependent variable: Life-Satisfaction. Controls for gender, marriage, cohabiting, children, health status, foreign-born, education, work status, interview form, time in panel, year of last interview, household size, age group, year of survey, regional unemployment and federal states are included. Standard errors clustered at the level of reference groups, robust t-statistics in parentheses. ${ }^{* *} \mathrm{p}<0.01,{ }^{* *} \mathrm{p}<0.05,{ }^{*} \mathrm{p}<0.1$.

Table 4 East Germany, SOEP, 2000-2010

\begin{tabular}{cccc}
\hline & $\mathbf{( 1 )}$ & $(\mathbf{2})$ & $\mathbf{( 3 )}$ \\
& All & $<\mathbf{4 5}$ & $>\mathbf{4 5}$ \\
\hline Pooled OLS & & & \\
Household income & $0.79^{* * *}$ & $0.61^{* * *}$ & $0.94^{* * *}$ \\
Comparison income & $(41.46)$ & $(22.49)$ & $(35.68)$ \\
& 0.05 & $0.28^{* * *}$ & $-0.10^{*}$ \\
Observations & $(1.02)$ & $(3.72)$ & $(-1.67)$ \\
Adj. R-squared & 56,456 & 23,562 & 32,894 \\
\hline
\end{tabular}

See Table 3. ${ }^{* *} \mathrm{p}<0.01,{ }^{* *} \mathrm{p}<0.05,{ }^{*} \mathrm{p}<0.1$.

As expected, in East Germany the income coefficient has a larger magnitude than in West Germany. In regions that are characterised by low income and high unemployment levels, own income has a higher relevance for individual well-being. In addition to this, results from the full sample indicate that comparison income does not matter for individuals in East Germany. Interestingly, splitting the sample suggests that the positive comparison effect for the under $45 \mathrm{~s}$ also holds in East Germany. 
In the next step, we exploit the panel structure of the SOEP and take into account individual time constant unobserved heterogeneity by including individual fixed effects. The corresponding results are presented in Tables 5 and 6. The results support our findings from the pooled OLS estimation: the influence of comparison income is different for young and old people. While young people experience higher life-satisfaction for higher peer incomes, older people experience the well-known relative deprivation effect with higher comparison income. An interesting artefact is that the positive comparison effect for the young is exactly offset by the usual negative comparison effect for those over 45 . So the net result for the whole sample is a zero coefficient for comparison, differing from all previous work with SOEP data that we are aware of where age groups are aggregated and the (net) effect of comparison income is negative. However, if we adopt the usual quadratic in age, we also find a negative effect of comparison in the whole sample - although this effect is only significant at the $10 \%$ level (see Section 4).

In East Germany, we find no comparison effects at all - apart from the case where we switch to a quadratic in age and consider the whole sample. This stands in contrast to Ferrer-i-Carbonell's (2005) random effects probit estimates and our own estimates from the pooled OLS model. The own-income coefficient is, as in the pooled OLS model, substantially larger than in the Western sample, which is plausible in a poorer region. A $50 \%$ rise in own income increases life satisfaction by approximately $4.9 \%$. Another result is that own income becomes more important with age in East and West Germany.

Table 5 West Germany, SOEP, 2000-2010

\begin{tabular}{|c|c|c|c|}
\hline & (1) & (2) & (3) \\
\hline & All & $<45$ & $>=45$ \\
\hline \multicolumn{4}{|l|}{ Fixed Effects } \\
\hline \multirow[t]{2}{*}{ Household income } & $0.25^{* * *}$ & $0.20^{* * *}$ & $0.29 * * *$ \\
\hline & (14.59) & $(8.46)$ & $(11.55)$ \\
\hline \multirow[t]{2}{*}{ Comparison income } & 0.00 & $0.21^{* *}$ & $-0.21^{* *}$ \\
\hline & $(0.07)$ & (2.19) & $(-2.48)$ \\
\hline Observations & 156,194 & 70,355 & 85,839 \\
\hline Number of persons & 26,711 & 14,700 & 14,893 \\
\hline Adj. R-squared & 0.0603 & 0.0682 & 0.0537 \\
\hline \multicolumn{4}{|c|}{$\begin{array}{l}\text { Dependent variable: Life-Satisfaction. Controls for marriag } \\
\text { interview form, time in panel, year of last interview, hous } \\
\text { and federal states are included. Standard errors clustered } \\
{ }^{* * *} p<0.01,{ }^{* *} p<0.05,{ }^{*} p<0.1 \text {. } \\
\text { Table } 6 \text { East Germany, SOEP, 2000-2010 }\end{array}$} \\
\hline & (1) & (2) & (3) \\
\hline & All & $<45$ & $>=45$ \\
\hline \multicolumn{4}{|l|}{ Fixed Effects } \\
\hline \multirow[t]{2}{*}{ Household income } & $0.38^{* * *}$ & $0.32^{* * *}$ & $0.43^{* * *}$ \\
\hline & $(12.13)$ & $(7.52)$ & (8.79) \\
\hline \multirow[t]{2}{*}{ Comparison income } & -0.01 & 0.13 & -0.11 \\
\hline & $(-0.08)$ & $(0.82)$ & $(-0.69)$ \\
\hline Observations & 56,456 & 23,562 & 32,894 \\
\hline Number of persons & 8,932 & 4,812 & 5,165 \\
\hline Adj. R-squared & 0.0574 & 0.0635 & 0.0521 \\
\hline
\end{tabular}

See Table 5. ${ }^{* * *} p<0.01,{ }^{* *} p<0.05,{ }^{*} p<0.1$. 
The pure age effects from the age-interval dummies in the full sample, fixed effects estimates (column (1) of Table 5 and column (1) of Table 6) are plotted in Figure 1. They are quite different from the frequently found U-shape in estimates without controlling for time spent in the panel and presence of an interviewer, and are actually hump-shaped in the West, while East Germany has a distinctive M-shaped pattern of happiness over the life-cycle. These results confirm Frijters and Beatton's (2012) and Kassenboehmer and Haisken-DeNew's (2012) main finding that fixed effects and the extra controls remove the U-shape.

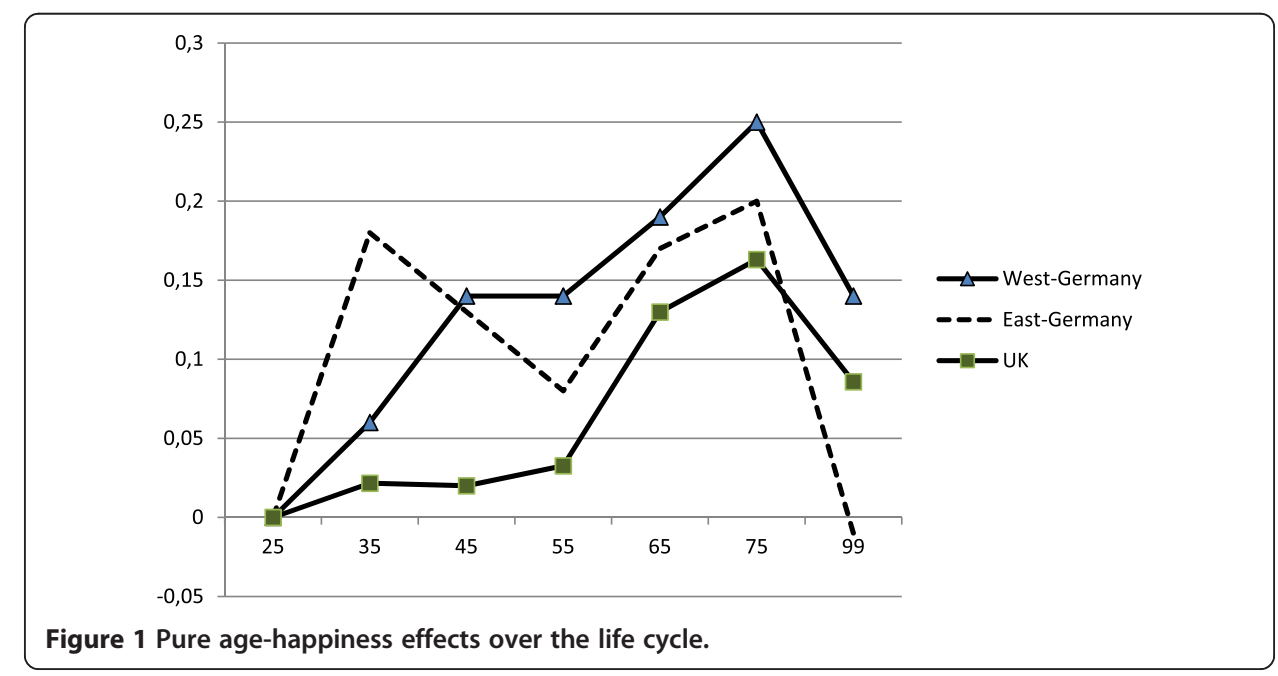

\subsection{Data and results for United Kingdom}

Our UK data ${ }^{9}$ are taken from Waves 6-10 and 12-18 of the British Household Panel Survey (BHPS), covering a period that runs from 1996/07 to 2008/09. We use data for 153,189 observations across 25,681 individuals, with those cases where there are missing values excluded. One point worthy of note is the deliberate over-sampling of the smaller nations of the UK since Wave 9 - so that about half of the individuals in the BHPS are from Scotland, Wales and Northern Ireland, compared to less than $20 \%$ in the overall population. While there are differences compared to England, they are much less than between West and East Germany, so do not warrant separate estimates. The range of coverage of this data set - which focuses on issues of interest to the social sciences and for policy purposes, across the members of a specific sample of households - is similarly broad as the SOEP, although unsurprisingly not identical.

In the BHPS data set, self-reported life-satisfaction is measured on a 7-point scale, 1 being the lowest value, while 7 is reported by individuals who are very satisfied with their life overall. For the identification of comparison income, we define an individual's reference group by gender, age $(-3 /+6)$, education (low or high), region (south of England, north of England, elsewhere in the UK (Scotland, Wales, Northern Ireland)) and BHPS wave (year). 
Table 7 Summary statistics, GB, waves 6-10 and UK, waves 12-18 (across 1996/97-2008/09)

\begin{tabular}{cccc}
\hline & $\mathbf{( 1 )}$ & $\mathbf{( 2 )}$ & $\mathbf{( 3 )}$ \\
& All & $<\mathbf{4 5}$ & $>\mathbf{4 5}$ \\
\hline Life-Satisfaction & $5.23(1.29)$ & $5.15(1.21)$ & $5.31(1.36)$ \\
Age & $45.57(18.38)$ & $30.66(8.32)$ & $61.52(11.53)$ \\
Household income & $2715.10(2155.56)$ & $3060.37(2102.17)$ & $2345.82(2066.91)$ \\
Comparison income & $2680.10(886.50)$ & $3060.16(622.30)$ & $2273.61(944.73)$ \\
$N$ & 153189 & 79168 & 74021 \\
\hline
\end{tabular}

See Table 1. Life satisfaction measures self-reported life-satisfaction on a 7-point scale. Household income measures real household income, using the Consumer Prices Index as deflator. Comparison income measures the average real household income within a reference group (Age (-3/+6), Sex, Education (2 categories), Regions (3 categories)) to which the respondent belongs. Source: BHPS.

Table 7 shows summary statistics for the BHPS data. To make approximate comparisons ${ }^{10}$ with overall life satisfaction in Germany, a simple linear transformation can be undertaken (subtract 1 , then multiply by $5 / 3$ ), so BHPS individuals have higher overall life satisfaction than in East Germany, but less than in West Germany. When the complete age range is considered, the UK average is pretty close to its counterpart from West Germany. However, for the younger age group, the BHPS average is relatively lower and nearer to its East German equivalent. The BHPS contrasts with the SOEP in that the older age group displays higher life satisfaction. This effect looks somewhat surprising given the $23 \%$ lower relative household income observed for the older age group in the UK case.

Table 8 UK, BHPS, Waves 6-10, 12-18

\begin{tabular}{|c|c|c|c|}
\hline & (1) & (2) & (3) \\
\hline & All & $<45$ & $>=45$ \\
\hline \multicolumn{4}{|l|}{ Pooled OLS } \\
\hline \multirow[t]{2}{*}{ Household income } & $0.086^{* * *}$ & $0.114^{* * *}$ & $0.054^{* * *}$ \\
\hline & $(14.86)$ & (15.09) & $(6.29)$ \\
\hline \multirow[t]{2}{*}{ Comparison income } & $-0.074^{* * *}$ & 0.037 & $-0.086^{* *}$ \\
\hline & $(-2.86)$ & $(0.94)$ & $(-2.37)$ \\
\hline Observations & 153,189 & 79,168 & 74,021 \\
\hline Adj. R-squared & 0.166 & 0.147 & 0.182 \\
\hline
\end{tabular}

Dependent variable: Life-Satisfaction. Controls for gender, marital status (including cohabiting), children, health status, education, work status, time in panel, year of last interview, household size, age group, wave number, regions and regional unemployment are included. Standard errors clustered at the level of reference groups, robust $t$-statistics in parentheses. ${ }^{* * *} p<0.01,{ }^{* *} p<0.05,{ }^{*} p<0.1$.

Table 8 covers pooled OLS estimates for the whole sample and the two age groups, reporting only household and comparison income variables. ${ }^{11}$ The negative effect of comparison income in the full UK sample is statistically significant, just like the West German case. As in our own earlier preliminary cross-sectional work on the BHPS, the comparison effect in the younger group remains statistically insignificant: by inspection, however, it does appear significantly different (in a negative direction) from the effect among the older age group $^{12}$. Using any of our preferred BHPS specifications from Table 8, we can conclude that the impacts of income on life satisfaction are very modest. For example, a 50\% increase in own (household) income would yield a predicted effect on life satisfaction of less than $1 \%$. By contrast, characteristics such as health and changes in marital status or economic activity status have more impact (around 7-10\%). 
Fixed effects results (Table 9) include a negative comparison income effect in the full sample, in contrast to West Germany. The sample split now very clearly demonstrates the difference between the two age ranges ${ }^{13}$ - with the comparison income effects statistically significant and positive in the younger group and of the opposite sign (and significant) in the older group. This pattern is very similar to West Germany.

Table 9 UK, BHPS, Waves 6-10, 12-18

\begin{tabular}{cccc}
\hline & $\mathbf{( 1 )}$ & $(\mathbf{2})$ & $\mathbf{( 3 )}$ \\
& All & $<\mathbf{4 5}$ & $>\mathbf{4 5}$ \\
\hline Fixed Effects & $0.039^{* * *}$ & $0.058^{* * *}$ & $0.018^{*}$ \\
Household income & $(6.16)$ & $(6.87)$ & $(1.92)$ \\
Comparison income & $-0.092^{* *}$ & $0.247^{* * *}$ & $-0.287^{* * *}$ \\
& $(-2.02)$ & $(3.22)$ & $(-4.46)$ \\
Observations & 153,189 & 79,168 & 74,021 \\
Number of persons & 25,681 & 16,327 & 12,034 \\
Adj. R-squared & 0.0374 & 0.0423 & 0.0336 \\
\hline
\end{tabular}

Dependent variable: Life-Satisfaction. Controls for marital status (including cohabiting), children, health status, education, work status, time in panel, year of last interview, household size, age group, wave number, regions and regional unemployment are included. Standard errors clustered at the individual level, robust t-statistics in parentheses. ${ }^{* * *} p<0.01,{ }^{* *} p<0.05,{ }^{*} p<0.1$.

Also, own household income has a relatively larger effect among the younger group (in contrast to the results for Germany) - and this effect is, rather surprisingly, much smaller throughout than the impact of comparison income. It is also much smaller than the own income effect in Germany (as also found by Helliwell et al. (2012), who did not, however, include comparison income). We are unaware of any explanation for this rather surprising finding.

The pure age effects are plotted in Figure 1 (column (1) of Table 9) and are very similar to West Germany.

\section{Robustness tests}

In the following section, we will present a series of additional results to assess the robustness of our empirical findings. We start with alternative measures of age. In view of widespread use of quadratic age controls, we have also estimated such models. The corresponding results in Tables 10, 11 and 12 shows that our main findings for the split samples are not affected if we follow the standard literature and capture age differences by a second-order polynomial, thus supporting the robustness of these findings. However, for the whole sample with all ages, the negative comparison effect now becomes significant for both West and East Germany, as other authors have found, and the t-value more than doubles for the UK. 
Table 10 West Germany, SOEP, 2000-2010

\begin{tabular}{cccc}
\hline & $\mathbf{( 1 )}$ & $\mathbf{( 2 )}$ & $\mathbf{( 3 )}$ \\
& All & $<\mathbf{4 5}$ & $>\mathbf{4 5}$ \\
\hline $\begin{array}{c}\text { Fixed Effects, age polynomial } \\
\text { Household income }\end{array}$ & $0.25^{* * *}$ & $0.20^{* * *}$ & $0.29^{* * *}$ \\
& $(14.41)$ & $(8.47)$ & $(11.34)$ \\
Comparison income & $-0.11^{*}$ & $0.26^{* * *}$ & $-0.27^{* * *}$ \\
& $(-1.96)$ & $(2.61)$ & $(-3.47)$ \\
Observations & 156,194 & 70,355 & 85,839 \\
Number of persons & 26,711 & 14,700 & 14,893 \\
Adj. R-squared & 0.0604 & 0.0682 & 0.0544 \\
\hline
\end{tabular}

Dependent variable: Life-Satisfaction. Controls for marriage, cohabiting, children, health status, education, work status, interview form, time in panel, year of last interview, household size, age and age squared, year of survey, regional unemployment and federal states are included. Standard errors clustered at the individual level, robust t-statistics in parentheses. ${ }^{* *} p<0.01,{ }^{* *} p<0.05,{ }^{*} p<0.1$.

Table 11 East Germany, SOEP, 2000-2010

\begin{tabular}{cccc}
\hline & $(\mathbf{1})$ & $\mathbf{( 2 )}$ & $\mathbf{( 3 )}$ \\
& All & $<\mathbf{4 5}$ & $>\mathbf{4 5}$ \\
\hline $\begin{array}{c}\text { Fixed Effects, age polynomial } \\
\text { Household income }\end{array}$ & $0.37^{* * *}$ & $0.32^{* * *}$ & $0.42^{* * *}$ \\
& $(11.94)$ & $(7.55)$ & $(8.70)$ \\
Comparison income & $-0.27^{* * *}$ & 0.05 & 0.01 \\
& $(-2.59)$ & $(0.32)$ & $(0.04)$ \\
Observations & 56,456 & 23,562 & 32,894 \\
Number of persons & 8,932 & 4,812 & 5,165 \\
Adj. R-squared & 0.0572 & 0.0630 & 0.0537 \\
\hline
\end{tabular}

See Table 10. ${ }^{* *} \mathrm{p}<0.01,{ }^{* *} \mathrm{p}<0.05,{ }^{*} \mathrm{p}<0$.

Table 12 UK, BHPS, Waves 6-10, 12-18

$\begin{array}{ccc}\begin{array}{c}(\mathbf{1}) \\ \text { All }\end{array} & \mathbf{( 2 )} & \begin{array}{c}(\mathbf{3}) \\ \mathbf{2}\end{array} \\ 0.039^{* * *} & & \\ (6.14) & 0.059^{* * *} & 0.018^{*} \\ 0.223^{* * *} & (7.02) & (1.89) \\ (-5.70) & 0.205^{* * *} & -0.157^{* * *} \\ 153,189 & (2.59) & (-2.88) \\ 25,681 & 79,168 & 74,021 \\ 0.0371 & 16,327 & 12,034 \\ & 0.0422 & 0.0347\end{array}$

Dependent variable: Life-Satisfaction. Controls for marital status (including cohabiting), children, health status, education, work status, time in panel, year of last interview, household size, age and age squared, wave number, regions and regional unemployment are included. Standard errors clustered at the individual level, robust t-statistics in parentheses. *** $p<0.01, * * p<0.05,{ }^{*} p<0.1$. 
Second, we undertook fixed effects estimation for a few more specification variants. Examples included different points (40 and 50) for the age split; and symmetric $(-5 /+5)$, rolling comparison income groups (see Layard et al. 2010). The corresponding results are reported in Tables 13, 14 and 15. Each of these variants yielded very similar results to their appropriate benchmark specification.

Table 13 West Germany, SOEP, 2000-2010

\begin{tabular}{|c|c|c|c|c|c|c|c|c|c|}
\hline & (1) & $(2)$ & (3) & (4) & (5) & (6) & (7) & (8) & (9) \\
\hline & All & $<40$ & $>=40$ & All & $<50$ & $>=50$ & All & $<45$ & $>=45$ \\
\hline \multicolumn{10}{|l|}{ Fixed Effects } \\
\hline & \multicolumn{2}{|c|}{ Age Split at 40} & & \multicolumn{3}{|c|}{ Age Split at 50} & \multicolumn{3}{|c|}{ Symmetric Ref Income $(-5,+5)$} \\
\hline \multirow[t]{2}{*}{ Household income } & $0.25^{* * *}$ & $0.17^{* * *}$ & $0.30^{* * *}$ & $0.25^{* * *}$ & $0.23^{* * *}$ & $0.25^{* * *}$ & $0.25^{* * *}$ & $0.20^{* * *}$ & $0.29^{* * *}$ \\
\hline & $(14.59)$ & $(6.47)$ & $(13.16)$ & $(14.59)$ & $(10.43)$ & $(8.97)$ & $(14.60)$ & $(8.48)$ & $(11.53)$ \\
\hline \multirow[t]{2}{*}{ Comparison income } & 0.00 & $0.24^{* *}$ & $-0.18^{* *}$ & 0.00 & $0.20^{* *}$ & $-0.27 * * *$ & -0.00 & $0.18^{*}$ & $-0.18^{* *}$ \\
\hline & $(0.07)$ & $(2.21)$ & $(-2.35)$ & $(0.07)$ & $(2.26)$ & $(-2.98)$ & $(-0.06)$ & $(1.84)$ & $(-2.14)$ \\
\hline Observations & 156,194 & 53,325 & 102,869 & 156,194 & 85,460 & 70,734 & 156,194 & 70,355 & 85,839 \\
\hline Number of persons & 26,711 & 12,161 & 17,635 & 26,711 & 16,861 & 12,365 & 26,711 & 14,700 & 14,893 \\
\hline Adj. R-squared & 0.0603 & 0.0643 & 0.0564 & 0.0603 & 0.0677 & 0.0494 & 0.0603 & 0.0682 & 0.0537 \\
\hline \multicolumn{10}{|c|}{ See Table 5. ${ }^{* *} p<0.01,{ }^{* *} p<0.05,{ }^{*} p<0.1$. } \\
\hline & (1) & (2) & (3) & (4) & (5) & (6) & (7) & (8) & (9) \\
\hline & All & $<40$ & $>=40$ & All & $<50$ & $>=50$ & All & $<45$ & $>=45$ \\
\hline \multicolumn{10}{|l|}{ Fixed Effects } \\
\hline & \multicolumn{3}{|c|}{ Age Split at 40} & \multicolumn{3}{|c|}{ Age Split at 50} & \multicolumn{3}{|c|}{ Symmetric Ref Income $(-5,+5)$} \\
\hline \multirow[t]{2}{*}{ Household income } & $0.38^{* * *}$ & $0.28^{* * *}$ & $0.48^{* * *}$ & $0.38^{* * *}$ & $0.35^{* * *}$ & $0.39^{* * *}$ & $0.38^{* * *}$ & $0.32^{* * *}$ & $0.43^{* * *}$ \\
\hline & (12.13) & $(6.22)$ & $(10.75)$ & $(12.13)$ & $(9.21)$ & (7.33) & $(12.19)$ & $(7.58)$ & (8.79) \\
\hline \multirow[t]{2}{*}{ Comparison income } & -0.01 & 0.22 & -0.23 & -0.01 & 0.14 & $-0.38^{* *}$ & -0.09 & -0.01 & -0.12 \\
\hline & $(-0.08)$ & $(1.28)$ & $(-1.47)$ & $(-0.08)$ & $(0.93)$ & $(-2.10)$ & $(-0.84)$ & $(-0.07)$ & $(-0.71)$ \\
\hline Observations & 56,456 & 18,080 & 38,376 & 56,456 & 29,300 & 27,156 & 56,456 & 23,562 & 32,894 \\
\hline Number of persons & 8,932 & 3,941 & 5,901 & 8,932 & 5,561 & 4,399 & 8,932 & 4,812 & 5,165 \\
\hline Adj. R-squared & 0.0574 & 0.0643 & 0.0557 & 0.0574 & 0.0659 & 0.0481 & 0.0574 & 0.0635 & 0.0521 \\
\hline
\end{tabular}

See Table 5. ${ }^{* * *} p<0.01,{ }^{* *} p<0.05,{ }^{*} p<0.1$.

Table 15 UK, BHPS, Waves 6-10, 12-18

\begin{tabular}{|c|c|c|c|c|c|c|c|c|c|}
\hline & (1) & (2) & (3) & (4) & (5) & (6) & (7) & (8) & (9) \\
\hline & All & $<40$ & $>=40$ & All & $<50$ & $>=50$ & All & $<45$ & $>=45$ \\
\hline \multicolumn{10}{|l|}{ Fixed Effects } \\
\hline & \multicolumn{3}{|c|}{ Age Split at 40} & \multicolumn{3}{|c|}{ Age Split at 50} & \multicolumn{3}{|c|}{ Symmetric Ref Income $(-5,+5)$} \\
\hline \multirow[t]{2}{*}{ Household income } & $0.039^{* * *}$ & $0.061^{* * *}$ & $0.019^{* *}$ & $0.039 * * *$ & $0.053^{* * *}$ & 0.012 & $0.039 * * *$ & $0.058^{* * *}$ & $0.018^{*}$ \\
\hline & (6.16) & $(6.51)$ & $(2.18)$ & $(6.16)$ & $(6.62)$ & $(1.19)$ & (6.14) & $(6.87)$ & $(1.89)$ \\
\hline \multirow[t]{2}{*}{ Comparison income } & $-0.092^{* *}$ & $0.248^{* * *}$ & $-0.244^{* * *}$ & $-0.092^{* *}$ & $0.276^{* * *}$ & $-0.353^{* * *}$ & $-0.082^{*}$ & $0.249^{* * *}$ & $-0.268^{* * *}$ \\
\hline & $(-2.02)$ & $(2.96)$ & $(-4.08)$ & $(-2.02)$ & (3.93) & $(-5.12)$ & $(-1.74)$ & (3.20) & $(-4.02)$ \\
\hline Observations & 153,189 & 64,583 & 88,606 & 153,189 & 92,129 & 61,060 & 153,189 & 79,168 & 74,021 \\
\hline Number of persons & 25,681 & 14,500 & 14,251 & 25,681 & 18,108 & 10,040 & 25,681 & 16,327 & 12,034 \\
\hline Adj. R-squared & 0.0374 & 0.0418 & 0.0348 & 0.0374 & 0.0420 & 0.0343 & 0.0374 & 0.0423 & 0.0335 \\
\hline
\end{tabular}

See Table 9. ${ }^{* *} p<0.01,{ }^{* *} p<0.05,{ }^{*} p<0.1$. 
Since health is correlated with happiness and income there is an endogeneity argument for omitting this variable, while the unemployed are in a basically different situation from others, as perhaps are young people and students still living at home. Thus we report three alternative sets of fixed effects estimates in Tables 16, 17, and 18, omitting health in columns $1-3$, the unemployed in columns $4-6$, and those younger than 25 in Germany (and younger than 22 in the UK, where education is typically completed earlier) in columns 7-9. None of the main results are much changed, except in East Germany, where comparison income for young people now becomes positive and significant when the unemployed are omitted.

Table 16 West Germany, SOEP, 2000-2010

\begin{tabular}{|c|c|c|c|c|c|c|c|c|c|}
\hline & (1) & (2) & (3) & (4) & (5) & (6) & (7) & (8) & (9) \\
\hline & All & $<45$ & $>=45$ & All & $<45$ & $>=45$ & All & $<45$ & $>=45$ \\
\hline \multicolumn{10}{|l|}{ Fixed Effects } \\
\hline & \multicolumn{3}{|c|}{ Without Health } & \multicolumn{3}{|c|}{ Without unemployed persons } & \multicolumn{3}{|c|}{ Without people $<25$} \\
\hline \multirow[t]{2}{*}{ Household income } & $0.26^{* * *}$ & $0.21^{* * *}$ & $0.30^{* * *}$ & $0.22^{* * *}$ & $0.17^{* * *}$ & $0.27^{* * *}$ & $0.30^{* * *}$ & $0.29^{* * *}$ & $0.29^{* * *}$ \\
\hline & $(14.72)$ & $(8.37)$ & $(11.74)$ & $(12.83)$ & $(6.93)$ & $(10.47)$ & $(15.81)$ & $(9.95)$ & $(11.55)$ \\
\hline \multirow[t]{2}{*}{ Comparison income } & -0.00 & $0.24^{* *}$ & $-0.23^{* * *}$ & 0.03 & $0.21^{* *}$ & $-0.17^{* *}$ & -0.03 & $0.27^{* *}$ & $-0.21^{* *}$ \\
\hline & $(-0.05)$ & $(2.43)$ & $(-2.76)$ & $(0.54)$ & $(2.22)$ & $(-2.07)$ & $(-0.46)$ & $(2.05)$ & $(-2.48)$ \\
\hline Observations & 156,194 & 70,355 & 85,839 & 150,314 & 67,305 & 83,009 & 142,079 & 56,240 & 85,839 \\
\hline Number of persons & 26,711 & 14,700 & 14,893 & 26,406 & 14,490 & 14,732 & 23,568 & 11,557 & 14,893 \\
\hline Adj. R-squared & 0.0372 & 0.0390 & 0.0363 & 0.0541 & 0.0569 & 0.0513 & 0.0605 & 0.0700 & 0.0537 \\
\hline
\end{tabular}

Table 17 East Germany, SOEP, 2000-2010

\begin{tabular}{|c|c|c|c|c|c|c|c|c|c|}
\hline & (1) & (2) & (3) & (4) & (5) & (6) & (7) & (8) & (9) \\
\hline & All & $<45$ & $>=45$ & All & $<45$ & $>=45$ & All & $<45$ & $>=45$ \\
\hline \multicolumn{10}{|l|}{ Fixed Effects } \\
\hline & \multicolumn{3}{|c|}{ Without Health } & \multicolumn{3}{|c|}{ Without unemployed persons } & \multicolumn{3}{|c|}{ Without people $<25$} \\
\hline \multirow[t]{2}{*}{ Household income } & $0.39^{* * *}$ & $0.32^{* * *}$ & $0.44^{* * *}$ & $0.36^{* * *}$ & $0.30^{* * *}$ & $0.41^{* * *}$ & $0.45^{* * *}$ & $0.44^{* * *}$ & $0.43^{* * *}$ \\
\hline & $(12.27)$ & (7.55) & $(8.91)$ & $(10.94)$ & $(6.81)$ & $(7.81)$ & $(12.63)$ & $(8.14)$ & (8.79) \\
\hline \multirow[t]{2}{*}{ Comparison income } & 0.01 & 0.16 & -0.11 & 0.07 & $0.35^{* *}$ & -0.18 & -0.09 & -0.11 & -0.11 \\
\hline & $(0.09)$ & $(0.97)$ & $(-0.63)$ & $(0.59)$ & $(2.07)$ & $(-1.10)$ & $(-0.75)$ & $(-0.50)$ & $(-0.69)$ \\
\hline Observations & 56,456 & 23,562 & 32,894 & 51,383 & 21,096 & 30,287 & 50,723 & 17,829 & 32,894 \\
\hline Number of persons & 8,932 & 4,812 & 5,165 & 8,683 & 4,621 & 5,011 & 7,811 & 3,691 & 5,165 \\
\hline Adj. R-squared & 0.0389 & 0.0402 & 0.0377 & 0.0491 & 0.0502 & 0.0487 & 0.0580 & 0.0648 & 0.0521 \\
\hline
\end{tabular}

See Table 5. ${ }^{* * *} p<0.01,{ }^{* *} p<0.05,{ }^{*} p<0.1$. 
Table 18 UK, BHPS, Waves 6-10, 12-18

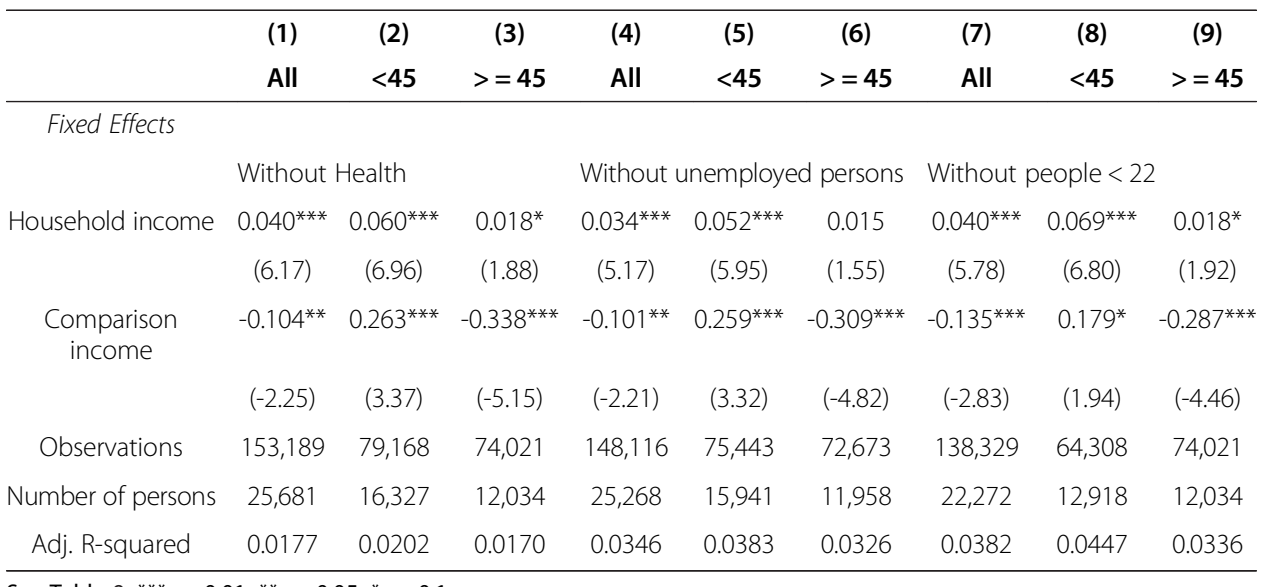

See Table 9. ${ }^{* *} p<0.01,{ }^{* *} p<0.05,{ }^{*} p<0.1$.

In Tables 19, 20, and 21 in the Appendix, we report estimates with standard errors clustered at the level of reference income instead of the individual level. See Moulton (1990) for a discussion about the use of (a) clustered standard for samples with aggregate and individual level variables. Our results are not affected by this measure.

Next, in Tables 22, 23, and 24 in the Appendix, we report estimates with interactions of comparison income with 10 year age-interval dummies and an interaction for over $45 .{ }^{14}$ These obviously provide more detail than just the two sub-samples, but essentially they confirm the main pattern, in particular the positive comparison effect for the under-45s in West but not East Germany and the stronger own-income benefits for the over-45s. In the East, there is just one significant negative comparison effect for the 55-64 groups.

In Table 24, column (1) pooled OLS estimation can be compared to the results shown in columns (2) and (3) of Table 9. The inclusion of comparison income interactions with age grouping dummies has negligible influence on the estimates for own household income. However, it becomes evident that the insignificant positive estimate for comparison income in column (2) of Table 9 is a consequence of an effect that is becoming less positive with increased age ${ }^{15}$. The negative estimate for comparison income in column (3) of Table 9 appears to originate principally from an effect in the 55-74 age range.

The UK results for own household income in column (2) of Table 24 correspond fairly obviously to those in Table 9. The fixed effects estimates for comparison income exhibit an even more obvious tendency towards a larger negative effect with advancing age. Although it may appear a little odd that none of the youngest three age groups have an overall effect of comparison income that is positive and significant, it should be recalled that column (2) of Table 24 constrains the disturbance correlation $^{16}$.

Finally, we summarise the results of additional tests, which support the robustness of our main results. ${ }^{17}$ At first, we constructed reference groups with fixed age categories instead of rolling age windows and alternative - or removed - regional restrictions. The West German results were preserved and East German comparison income was 
consistently insignificant. The regional restriction is obviously needed in the UK, with major income disparities between the North and Southeast, and alternative comparison groups preserved signs but lost significance.

The BHPS includes a financial expectations variable, and we find that among the younger group, only those with optimistic expectations have a positive and significant response to comparison income, a nice confirmation of the signalling or tunnel effect. However splitting the whole sample just by the expectations variable did not yield clear results like our age split. In SOEP, similar expectations variables are not available for all years.

\section{Policy conclusions}

Economic policy is generally focussed on growth of GDP, not only because falling GDP means rising unemployment, but also because higher incomes are assumed to make people happier in the long run. However most rich countries show no upward trend in life satisfaction or happiness despite decades of economic growth and a strong cross-sectional relationship between individual income and life satisfaction, the famous paradox named after Easterlin (1974, 2013). Negative comparison income effects are widely cited as one explanation, but we find this only for the older population, which cancels the positive comparison effect for the younger to give a zero overall effect in fixed effects estimates for Germany. Thus our results provide an additional explanation for the observed trends in happiness in some industrialised/developed countries, including Germany (but not the UK), with ageing populations and shrinking shares of young people (who are likely to experience gains in well-being from increasing comparison income and economic growth) where average happiness is more likely to stagnate.

We also confirm Frijters and Beaton's (2012) and other recent contributions that find a strong negative effect of age for respondents over 75 (in contrast to the traditional U-shaped age-happiness relation). So an increasingly older population share with declining life satisfaction is an important factor offsetting the benefits of real income growth. Particularly given the very unfavourable demographic trends in Germany, an important policy conclusion is that much more attention should be given directly to the well-being of the elderly instead of just relying on rising income with economic growth, which may well be offset by rising care costs for many and does not address other important factors for life satisfaction.

In our UK estimates, we confirm previous findings of a very small own-income effect (Pfaff, 2013), which is difficult to explain, and find a much larger comparison effect, negative for the whole sample, but again positive for the younger group. This might suggest declining average life satisfaction in the UK, though it has less of an aging problem than Germany. But in fact, the life satisfaction trend is also essentially flat. This is particularly noteworthy because average income of the over $45 \mathrm{~s}$ is about $20 \%$ lower, and their life satisfaction is slightly higher than in the younger group in the UK. By contrast, the (proportionately larger) older group in Germany has the same average income (partly due to more generous pensions) but lower life satisfaction than the younger. Nonmonetary factors such as health, social interactions and employment are relatively more important in the UK than in Germany (due to weak own-income effects). So again, though for somewhat different reasons, policy priority for economic growth is difficult to justify in terms of well-being ${ }^{18}$. 
Our results imply that the estimation of comparison income effects in samples drawn from the full age range, as in most previous work, misses important differences. In addition, absolutely declining well-being of a growing elderly population adds another dimension to the failure of current economic policies to systematically increase average life satisfaction in rich countries. Clearly, further research is needed to provide more detailed explanations of this failure and to guide policy towards raising the life satisfaction of all age groups.

\section{Appendix}

A1: Definition of reference income

Germany

We define an individual's comparison group by gender, age, education, region and time. In the case of age, we construct a rolling criterion $(-3,+6)$, assuming that an individual at a particular date compares with peers up to 3 years younger and 6 years older - except where explicitly stated as otherwise. With respect to education, we rely on levels of schooling (low, medium and high). The lowest level is being in school, having basic schooling or having dropped out of school. The highest level is Abitur or advanced secondary education (Fachhochschulreife), which allow people to attend universities or, respectively, technical colleges. In the case of West German regions, we distinguish between four regions (West, North, Southwest, and South), which are defined as the following: West: Lower Saxony and North Rhine-Westphalia; North: Bremen, Hamburg and Schleswig-Holstein; Southwest: Rhineland-Palatinate and Saarland; South: Hesse, Baden-Wuerttemberg and Bavaria. In the case of the East German regions, we distinguish between the North (Berlin, Brandenburg and Mecklenburg-Vorpommern) and the South (Saxony, Saxony-Anhalt and Thuringia). In addition to this, we calculate reference income for every given year (2000-2010).

UK

As with Germany, an individual's comparison group is defined by gender, age, education, region and time. The rolling criterion $(-3,+6)$ is again used (except for one exception), so that an individual compares, at a particular date, with peers up to 3 years younger and 6 years older. For education, only two categories of schooling are defined (low and high), using ISCED $^{19}$ based definitions. In this case, 'low' encompasses primary, secondary, lower vocational and middle vocational education. 'High' covers higher vocational education, plus first degrees and higher degrees. For regions, our three UK regions capture (respectively): London and the south of England, the rest of England, and the rest of the UK (Wales, Scotland and Northern Ireland). Comparison income is calculated for each BHPS Wave - our data for Waves 6-10 and 12-18 cover the period 1996/97 to 2008/09 (with a break for Wave 11, in which data for the life satisfaction variable were not collected).

\section{A2: Additional Results}

Tables 19, 20, and 21 and Tables 22, 23, and 24. 
Table 19 West Germany, SOEP, 2000-2010

\begin{tabular}{lccc}
\hline & $\mathbf{( 1 )}$ & $\mathbf{( 2 )}$ & $\mathbf{( 3 )}$ \\
& All & $<\mathbf{4 5}$ & $>\mathbf{4 5}$ \\
\hline Fixed Effects & & & \\
Household income & $0.25^{* * *}$ & $0.20^{* * *}$ & $0.29^{* * *}$ \\
Comparison income & $(17.63)$ & $(10.24)$ & $(13.79)$ \\
& 0.00 & $0.21^{* * *}$ & $-0.21^{* * *}$ \\
Observations & $(0.08)$ & $(2.60)$ & $(-2.83)$ \\
Number of persons & 156,194 & 70,355 & 85,839 \\
Adj. R-squared & 26,711 & 14,700 & 14,893 \\
\hline
\end{tabular}

Dependent variable: Life-Satisfaction. Controls for marriage, cohabiting, children, health status, education, work status, interview form, time in panel, year of last interview, household size, age group, year of survey and federal states are included. Standard errors clustered at the level of reference income, robust $t$-statistics in parentheses. ${ }^{* * *} \mathrm{p}<0.01$, ${ }^{* *} \mathrm{p}<0.05,{ }^{*} \mathrm{p}<0.1$.

Table 20 East Germany, SOEP, 2000-2010

\begin{tabular}{lccc}
\hline & $(\mathbf{1})$ & $(\mathbf{2})$ & $\mathbf{( 3 )}$ \\
& All & $<\mathbf{4 5}$ & $\mathbf{4} \mathbf{4 5}$ \\
\hline Fixed Effects & & & $0.43^{* * *}$ \\
Household income & $0.38^{* * *}$ & $0.32^{* * *}$ & $(10.29)$ \\
& $(14.42)$ & $(9.02)$ & -0.11 \\
Comparison income & -0.01 & 0.13 & $(-0.84)$ \\
& $(-0.09)$ & $(0.97)$ & 32,894 \\
Observations & 56,456 & 23,562 & 5,165 \\
Number of persons & 8,932 & 4,812 & 0.0521 \\
Adj. R-squared & 0.0574 & 0.0635 &
\end{tabular}

See Table 19. ${ }^{* *} \mathrm{p}<0.01,{ }^{* *} \mathrm{p}<0.05,{ }^{*} \mathrm{p}<0.1$.

Table 21 UK, BHPS, Waves 6-10, 12-18

\begin{tabular}{ccc}
$\mathbf{( 1 )}$ & $(\mathbf{2})$ & $(\mathbf{3})$ \\
All & $<\mathbf{4 5}$ & $>=\mathbf{4 5}$ \\
\hline $0.039^{* * *}$ & & \\
$(7.07)$ & $0.058^{* * *}$ & $0.018^{* *}$ \\
$-0.092^{* *}$ & $(7.76)$ & $(2.20)$ \\
$(-2.43)$ & $0.247^{* * *}$ & $-0.287^{* * *}$ \\
153,189 & $(3.77)$ & $(-5.42)$ \\
25,681 & 79,168 & 74,021 \\
0.0374 & 16,327 & 12,034 \\
& 0.0423 & 0.0336
\end{tabular}

Dependent variable: Life-Satisfaction. Controls for marital status (including cohabiting), children, health status, education, work status, time in panel, year of last interview, household size, age group, wave number, regions and regional unemployment are included. Standard errors clustered at the level of reference income, robust t-statistics in parentheses. ${ }^{* * *} p<0.01, * * p<0.05,{ }^{*} p<0.1$. 
Table 22 West Germany, SOEP, 2000-2010

(1)

(2)

Pooled OLS

Fixed effects

Interacted Model, full sample

Household income

$0.43^{* * *}$

$0.21^{* * *}$

Household income* $45+$

(27.69)

(9.39)

$0.18^{* * *}$

$0.08^{* * *}$

Comparison income

(8.62)

Comparison income

$0.57^{* * *}$

$0.33^{* * *}$

Comparison income ${ }^{*}$ 25-34

(5.99)

(2.60)

Comparison income* 25-34

$-0.48^{* * *}$

$-0.29^{* *}$

$(-4.01)$

$(-1.98)$

Comparison income* $35-44$

$-0.50^{* * *}$

$-0.21$

$(-4.78)$

$(-1.46)$

Comparison income* 45-54

$-0.86^{* * *}$

$-0.52^{* * *}$

$(-8.04)$

Comparison income* $55-64$

$-0.88^{* * *}$

$-0.54^{* * *}$

$(-8.38)$

$(-3.68)$

Comparison income* $65-74$

$-0.65^{* * *}$

$-0.44^{* * *}$

$(-6.23)$

Comparison income* $75+$

$-0.53^{* * *}$

$-0.55^{* * *}$

$(-4.40)$

$(-3.05)$

Observations

156,194

156,194

Number of persons

26,711

26,711

Adj. R-squared

0.204

0.0615

Dependent variable: Life-Satisfaction. In addition to the variables listed in Tables 3 and 5, controls for interactions of all explanatory variables with a dummy for being older than 44 are included. Reference group of age groups: 18-24. ${ }^{* * *} p<0.01, * * p<0.05,{ }^{*} p<0.1$. 
Table 23 East Germany, SOEP, 2000-2010

(1)

Pooled OLS

Interacted Model, full sample

Household income

Household income* $45+$

Comparison income

Comparison income* $25-34$

Comparison income* $35-44$

Comparison income* $45-54$

Comparison income* $55-64$

Comparison income* $65-74$

Comparison income* $75+$

Observations

Number of persons
$0.61^{* * *}$

(22.50)

$0.33^{* * *}$

(8.80)

$0.32^{* *}$

(1.99)

$-0.06$

$(-0.31)$

$-0.04$

$(-0.20)$

$-0.35^{* *}$

$(-1.96)$

$-0.67^{* * *}$

$(-3.62)$

$-0.21$

$(-0.98)$

$-0.01$

56,456

8,932

0.225
(2)

Fixed effects

$0.35^{* * *}$

(8.84)

$0.09^{*}$

(1.73)

0.31

(1.46)

$-0.23$

$(-0.90)$

$-0.16$

$(-0.63)$

$-0.35$

$(-1.39)$

$-0.65^{* *}$

$(-2.50)$

$-0.24$

$(-0.79)$

$-0.33$

56,456

8,932

0.0592

Dependent variable: Life-Satisfaction. In addition to the variables listed in Tables 4 and 6, controls for interactions of all explanatory variables with a dummy for being older than 44 are included. Reference group of age groups: 18-24. *** $p<0.01,{ }^{* *} p<0.05,{ }^{*} p<0.1$. 
Table 24 UK, BHPS, Waves 6-10, 12-18

\begin{tabular}{|c|c|c|}
\hline & $\begin{array}{c}\text { (1) } \\
\text { Pooled OLS }\end{array}$ & $\begin{array}{c}\text { (2) } \\
\text { Fixed effects }\end{array}$ \\
\hline \multicolumn{3}{|l|}{ Interacted Model, full sample } \\
\hline \multirow[t]{2}{*}{ Household income } & $0.115^{* * *}$ & $0.055^{* * *}$ \\
\hline & (15.14) & $(6.65)$ \\
\hline \multirow[t]{2}{*}{ Household income $45+$} & $-0.060^{* * *}$ & $-0.038^{* * *}$ \\
\hline & $(-5.23)$ & $(-3.13)$ \\
\hline \multirow[t]{2}{*}{ Comparison income } & $0.114^{*}$ & 0.112 \\
\hline & $(1.70)$ & $(1.19)$ \\
\hline \multirow[t]{2}{*}{ Comparison income* 25-34 } & -0.034 & 0.028 \\
\hline & $(-0.53)$ & $(0.36)$ \\
\hline \multirow[t]{2}{*}{ Comparison income* $35-44$} & $-0.146^{* *}$ & -0.007 \\
\hline & $(-2.20)$ & $(-0.08)$ \\
\hline \multirow[t]{2}{*}{ Comparison income $e^{*} 45-54$} & -0.036 & -0.136 \\
\hline & $(-0.43)$ & $(-1.18)$ \\
\hline \multirow[t]{2}{*}{ Comparison income* 55-64 } & $-0.234^{* * *}$ & $-0.230^{* *}$ \\
\hline & $(-2.93)$ & $(-2.00)$ \\
\hline \multirow[t]{2}{*}{ Comparison income* $65-74$} & $-0.296^{* * *}$ & $-0.375^{* * *}$ \\
\hline & $(-3.72)$ & $(-3.14)$ \\
\hline \multirow[t]{2}{*}{ Comparison income* $75+$} & -0.152 & $-0.719^{* * *}$ \\
\hline & $(-1.60)$ & $(-5.03)$ \\
\hline Observations & 153,189 & 153,189 \\
\hline Number of persons & 25,681 & 25,681 \\
\hline Adj. R-squared & 0.170 & 0.0388 \\
\hline
\end{tabular}

Dependent variable: Life-Satisfaction. In addition to the variables listed in Tables 8 and 9, controls for interactions of all explanatory variables with a dummy for being at least 45 are included. Reference group of age groups: under 25 . ${ }^{* * *} p<0.01, * * p<0.05,{ }^{*} p<0.1$.

\section{A3: A Model of happiness over the life cycle} Theory

In this section, we set out a model that supports our empirical findings - specifically the finding that in the early stages of working life, the average income of the comparison group may have either a positive or insignificant effect on reported happiness or life-satisfaction.

The essential insight we wish to capture is that life-satisfaction may depend on not just a comparison of a person's own current income with the current income of their peers, but also on a comparison of how their life as a whole is going relative to their peers, thus on relative lifetime income. Of course, early in their working life people do not know for sure how their lives might pan out and, in particular, how not just their own lifetime income but that of the comparison group will evolve. So they use information about how their life has gone to date - specifically their current income and that of their peers - to draw inferences about how things might go in the future. In this context a high current income of the comparison group may signal that there has been a significant amount of promotion to date, and hence future promotion prospects and expectations of relative future lifetime income are good.

The aim of the model is to formalise this idea and show that there are indeed contexts in which, in the earlier part of working life, the current income of the comparison group may be positively associated with reported happiness. 


\section{The Model}

The model is framed in a way that is consistent with the data on which the empirical analysis has been conducted. So it is assumed that individuals' working lives are split into two periods.

We also assume that all individuals have a comparison/peer group with whom they compare how their lives are going. Accordingly, we consider a sub-population of individuals who are identical in terms of some observable characteristics: age, educational attainment, location etc. This constitutes the comparison/peer group to which everyone within the sub-population compares themselves.

Though identical in certain respects, individuals differ in some other characteristics that are unobservable but will manifest over the course of their lifetime in two different respects:

- Individuals may turn out to be Hares or Tortoises. Hares show early promise and get promoted early (in period 1). Tortoises develop more slowly, and get promoted, if at all, later in life - in period 2. Individuals learn in period 1 whether or not they have been promoted and hence whether they are Hares or Tortoises. So in period 1, the current income of a Tortoise is $c_{1}^{T}=b$, where $b>0$ denotes basic income, while the current income of a Hare is $c_{1}^{H}=b(1+\varphi)$, where $\varphi>0$ is the proportionate income supplement obtained through promotion in Period 1.

- Individuals may turn out to be genuinely smart or basically dull. Smartness only manifests itself in period 2 and leads to smart people - Tortoises or Hares - being promoted (or further promoted) in Period 2. It is assumed that Smart Tortoises turn out to be equally smart as Smart Hares; therefore, in period 2, their current incomes are $c_{2}^{S T}=c_{2}^{S H}=b(1+\sigma+\varphi)$, where $\sigma>0$ represents a smartness factor - the extent to which promoted people get an extra income supplement to reflect the value of real smartness rather than the flashiness of a Hare. In Period 2, some of the Hares who were promoted in Period 1 will turn out not to actually have much substance and will be Dull Hares. Having already been promoted they tread water in terms of income and in period 2 get current income $c_{2}^{D H}=b(1+\varphi)$. Finally Dull Tortoises don't get promoted in period 2 either and thus end up with current income $c_{2}^{D T}=b$.

For simplicity it is assumed that these two manifested characteristics - flashiness and smartness - are independently distributed in the population. Let $p_{H}, \quad 0<p_{H}<1$ be the proportion of people who are Hares, and $p_{S}, \quad 0<p_{S}<1$ be the proportion of people who are smart.

In period 1 the average current income of the group is

$$
\bar{c}_{1}=p_{H} c_{1}^{H}+\left(1-p_{H}\right) c_{1}^{T}=b\left(1+p_{H} \varphi\right),
$$

while in period 2 it is

$$
\bar{c}_{2}=b\left[1+p_{S}(\sigma+\varphi)+\left(1-p_{S}\right) p_{H} \varphi\right]=\bar{c}_{1}+p_{S} b\left[\sigma+\varphi\left(1-p_{H}\right)\right]
$$

It is assumed that the happiness experienced by each person in each period depends on 
i. A comparison of their current income with the average current income of their peers.

ii. A comparison of their view of their lifetime income with the average lifetime income of their peers. In Period 1, lifetime income is not fully known, so individuals have to estimate both their own lifetime income and the average lifetime income of their peers.

It follows from the above assumptions that at the end of Period 1:

- the expected lifetime income of a Hare is

$$
y_{1}^{e H}=2 c_{1}^{H}+p_{S} b \sigma
$$

- the expected lifetime income of a Tortoise is

$$
y_{1}^{e T}=2 c_{1}^{T}+p_{S} b(\sigma+\varphi)
$$

- the expected average lifetime income of the peer group is

$$
\bar{y}_{1}=2 \bar{c}_{1}+p_{S} b\left[\sigma+\varphi\left(1-p_{H}\right)\right] .
$$

Now suppose that although for individuals the probability of being smart is the same whether they are a Hare or a Tortoise, in the population as a whole, the proportion of smart people is related to the proportion of Hares by ${ }^{20}$

$$
p_{S}=p_{H}
$$

It follows from this that at the end of Period 1:

- the expected lifetime income of a Hare is

$$
y_{1}^{e H}=2 c_{1}^{H}+p_{H} b \sigma
$$

- the expected lifetime income of a Tortoise is

$$
y_{1}^{e T}=2 c_{1}^{T}+p_{H} b(\sigma+\varphi)
$$

- the expected average lifetime income of the peer group is

$$
\bar{y}_{1}=2 \bar{c}_{1}+\left(p_{H} b\right)(\sigma+\varphi)-\left(p_{H} b\right)^{2} \frac{\varphi}{b}
$$

\section{Information structure}

The information structure of the model is as follows. 
- At the outset, and throughout their lives, individuals know: the values of $\varphi$ and $\sigma$ the income premiums to flashiness and smartness respectively; the relationship between Period 1 and Period 2 incomes, conditional on being of various types; and the relationship between $p_{S}$ and $p_{H}$ as given by (A1).

- However, initially they do not know the economic prospects for their cohort whether they have skills that will turn out to be in high demand and lead to high opportunities for promotion. That is, initially they do not know the values of $b$ and $p_{H}$.

- However, in Period 1 they learn their own income and that of their peers, and so by comparing them, they know whether they have turned out be a Hare or a Tortoise. Formally, they learn: $c_{1}^{j}, \quad j=H, T$; the average income of their peers, $\bar{c}_{1}$; their current income relative to that of their peers, ${ }^{c} r_{1}^{j}=\frac{c_{1}^{j}}{\bar{c}_{1}}, j=H, T$ and hence their type $H$ or $T$. Also from what they learn in Period 1, they can deduce the values of $b$ and $p_{H}$ and, hence, from (A1), the value of their future promotion prospects, $p_{S}$. Using this, they can use (A2), (A3) and (A4) to calculate their own expected lifetime income and the average of that of their peers.

- In Period 2 everything is revealed. Individuals learn the value of their current income in Period 2 and the average current income of their peers. Comparing their current income in Period 2 to that earned in Period 1, they learn whether they are smart or dull. So they now fully know their type. They can now carry out a full comparison of how their life has gone relative to their peers in terms of both their relative current income and their relative lifetime income. Formally individuals learn their Period 2 income $c_{2}^{j k}, \quad j=S, D ; \quad k=H, T$ and hence their type $j k, j=S, D ; k=H, T$. They also learn the average Period 2 income of their peers $\bar{c}_{2} \cdot{ }^{21}$ Individuals therefore know their full lifetime income $y_{2}^{j k}=c_{1}^{k}+c_{2}^{j k}, \quad j=S, D ; k=H, T$ and the average lifetime income of their peers: $\bar{y}_{2}=\bar{c}_{1}+\bar{c}_{2}$.

\section{Implications}

Having set out the assumptions of the model, we now derive the implications. The fundamental issue we want to investigate is how the average current income of the peer group in each of the two periods affects each individual's reported happiness, taking as given their own income. In particular, we want to explore the possibility that although a higher level of peer income in Period 1 lowers relative current income, it might raise expected relative lifetime income since it sends a signal about higher promotion prospects in the future.

\section{Unfolding Lives}

Period 1

Hares

In Period 1, Hares learn their current income $c_{1}^{H}=b(1+\varphi)$ and the average income of their peers $\bar{c}_{1}=b\left(1+p_{H} \varphi\right)$. Hence they know their relative current Period 1 income

$$
{ }^{c} r_{1}^{H}=\frac{c_{1}^{H}}{\bar{c}_{1}}>1
$$

which is, of course, a strictly decreasing function of the average Period 1 income of their peers. 
From this they calculate:

$$
b=\frac{c_{1}^{H}}{1+\varphi} ; \quad b p_{H}=\frac{\bar{c}_{1}(1+\varphi)-c_{1}^{H}}{\varphi(1+\varphi)}
$$

Substitute (A5) into (A2) and (A4) to get:

$$
\begin{aligned}
& y_{1}^{e H}=\frac{2 \varphi(1+\varphi) c_{1}^{H}+\sigma\left[\bar{c}_{1}(1+\varphi)-c_{1}^{H}\right]}{\varphi(1+\varphi)} \\
& \bar{y}_{1}^{H}=\frac{2 \varphi(1+\varphi) \bar{c}_{1}+(\sigma+\varphi)\left[\bar{c}_{1}(1+\varphi)-c_{1}^{H}\right]-\left[\bar{c}_{1}(1+\varphi)-c_{1}^{H}\right]^{2}{\frac{1}{c_{1}^{H}}}^{H}}{\varphi(1+\varphi)}
\end{aligned}
$$

where $\bar{y}_{1}^{H}$ is the average lifetime income that Hares expect their peers to get on the basis of the information available to Hares in Period 1.

It is straightforward to show that

$$
\frac{\partial \bar{y}_{1}^{H}}{\partial \bar{c}_{1}}=\frac{(\sigma+\varphi)+2\left(1-p_{H}\right) \varphi}{\varphi}>\frac{\sigma}{\phi}=\frac{\partial y_{1}^{e H}}{\partial \bar{c}_{1}}>0,
$$

so, other things being equal, the higher the current income of their peers, the higher the realised proportion of Hares in the population, and thus, from (A1), the greater the promotion prospects they face in Period 2. This raises Hares' estimated value of their own lifetime income, but also that of their peers, and indeed the latter increases by more than the former.

Now from (A6) and (A7), in Period 1, Hares expect to end up with a relative lifetime income:

$$
\begin{aligned}
{ }_{r_{1}}^{e H} & =\frac{y_{1}^{e H}}{\bar{y}_{1}^{H}} \\
& =\frac{2 \varphi(1+\varphi) c_{1}^{H}+\sigma\left[\bar{c}_{1}(1+\varphi)-c_{1}^{H}\right]}{2 \varphi(1+\varphi) \bar{c}_{1}+(\varphi+\sigma)\left[\bar{c}_{1}(1+\varphi)-c_{1}^{H}\right]-\left[\bar{c}_{1}(1+\varphi)-c_{1}^{H}\right]^{2} \frac{1}{c_{1}^{H}}}
\end{aligned}
$$

It is straightforward to show that

$$
{ }_{r_{1}}^{e H}=\frac{2(1+\varphi)+\sigma p_{H}}{\left[2(1+\varphi)+\sigma p_{H}\right]-\varphi\left(1-p_{H}\right)-\varphi\left(1-p_{H}\right)^{2}}>1
$$

and thus, as we know must be the case, the expected lifetime income of Hares is greater than the expected lifetime income of their peers.

By differentiating (A9) w.r.t $\bar{c}_{1}$ we get:

$$
\frac{\partial^{y} r_{1}^{e H}}{\partial \bar{c}_{1}}=\frac{\frac{\partial y_{1}^{e H}}{\partial \bar{c}_{1}}-{ }^{y} r_{1}^{e H} \frac{\partial \bar{y}_{1}^{H}}{\partial \bar{c}_{1}}}{\bar{y}_{1}^{\mathrm{H}}}
$$

which from (A8) and (A10) is strictly negative. So the relative lifetime income expected by Hares in period 1 is a decreasing function of average current income of their peers, and so too is their happiness. 


\section{Tortoises}

In Period 1, Tortoises learn their current income $c_{1}^{T}=b$ and the average income of their peers, $\bar{c}_{1}=b\left(1+p_{H} \varphi\right)$. Hence they know their relative current Period 1 income

$$
{ }^{c} r_{1}^{T}=\frac{c_{1}^{T}}{\bar{c}_{1}}<1
$$

which is, of course, a strictly decreasing function of the average Period 1 income of their peers.

From this information, Tortoises can also work out:

$$
b=c_{1}^{T} ; \quad b p_{H}=\frac{\bar{c}_{1}-c_{1}^{T}}{\varphi}
$$

Substitute (A13) into (A3) and (A4) to get:

$$
\begin{aligned}
& y_{1}^{e T}=\frac{2 \varphi c_{1}^{T}+(\sigma+\varphi)\left(\bar{c}_{1}-c_{1}^{T}\right)}{\varphi} \\
& \bar{y}_{1}^{T}=\frac{2 \varphi \bar{c}_{1}+(\sigma+\varphi)\left(\bar{c}_{1}-c_{1}^{T}\right)-\left(\bar{c}_{1}-c_{1}^{T}\right)^{2} \frac{1}{c_{1}^{T}}}{\varphi},
\end{aligned}
$$

where $\bar{y}_{1}^{T}$ is the average lifetime income that Tortoises expect their peers to get on the basis of the information available to Tortoises in Period 1.

It is straightforward to show that

$$
\frac{\partial \bar{y}_{1}^{T}}{\partial \bar{c}_{1}}=\frac{(\sigma+\varphi)+2\left(1-p_{H}\right) \varphi}{\varphi}>\frac{\sigma+\varphi}{\varphi}=\frac{\partial y_{1}^{e T}}{\partial \bar{c}_{1}}>0,
$$

so, just as with Hares, the higher the current income of their peers, the higher the realised proportion of Hares in the population, and thus so, from (A1), the greater the promotion prospects that Tortoises face in Period 2. This raises Tortoises' estimated value of their own lifetime income, but also that of their peers, and indeed the latter increases by more than the former.

Now from (A14) and (A15), in Period 1, Tortoises expect to end up with a relative lifetime income:

$$
{ }^{y} r_{1}^{e T}=\frac{y_{1}^{e T}}{\bar{y}_{1}^{T}}=\frac{2 \varphi c_{1}^{T}+(\sigma+\varphi)\left(\bar{c}_{1}-c_{1}^{T}\right)}{2 \varphi \bar{c}_{1}+(\sigma+\varphi)\left(\bar{c}_{1}-c_{1}^{T}\right)-\left(\bar{c}_{1}-c_{1}^{T}\right)^{2} \frac{1}{c_{1}^{T}}}
$$

It is straightforward to show that

$$
{ }^{y} r_{1}^{e T}=\frac{2+(\sigma+\varphi) p_{H}}{\left[2+(\sigma+\kappa) p_{H}\right]+\varphi p_{H}\left(2-p_{H}\right)}<1,
$$


and thus, as we know must be the case, the expected lifetime income of Tortoises is lower than the expected lifetime income of their peers.

By differentiating (A18) w.r.t $\bar{c}_{1}$ we get:

$$
\frac{\partial^{y} r_{1}^{e T}}{\partial \bar{c}_{1}}=\frac{\frac{\partial e_{1}^{e T}}{\partial \bar{c}_{1}}-{ }^{y} r_{1}^{e T} \frac{\partial \bar{y}_{1}^{T}}{\partial \bar{c}_{1}}}{\bar{y}_{1}^{T}}
$$

Consequently,

$$
\frac{\partial^{y} r_{1}^{e T y}}{\partial \bar{c}_{1}} \frac{<}{<} 0 \Leftrightarrow \frac{\frac{\partial y_{1}^{e T}}{\partial \bar{c}_{1}}}{\frac{\partial \bar{y}_{1}^{T}}{\partial \bar{c}_{1}}} \frac{}{<}^{y} r_{1}^{e T}
$$

Substitute (A16) into (A20), and we get:

$$
\frac{\partial^{y} r_{1}^{e T}}{\partial \bar{c}_{1}} \geq 0 \Leftrightarrow \frac{\sigma+\varphi}{<}=\frac{2+(\sigma+\varphi) p_{H}}{(\sigma+\varphi)+2\left(1-p_{H}\right) \varphi}<\frac{\left.2-p_{H}\right)}{2+(\sigma+\varphi) p_{H}+\varphi p_{H}(2-p}
$$

It is clear that if $p_{H}=0$, then $\frac{\partial^{y} y_{1}^{e T}}{\partial \bar{c}_{1}}<0$, whereas if $p_{H}=1$, then $\frac{\partial^{y} y_{1}^{e T}}{\partial \bar{c}_{1}}>0$. So the conclusion is that if $p_{H}$ is sufficiently large, then an increase in the average income earned by their peers in Period 1 raises the expected relative lifetime income of Tortoises and, hence, potentially their happiness.

\section{Period Two}

This is straightforward.

Each type of individual knows their current Period 2 income, $c_{2}^{j k}, \quad j=S, D ; \quad k=H, T$ and the average Period 2 income of their peers, $\bar{c}_{2}$. Consequently, they can work out their relative current income

$$
{ }^{c} r_{2}^{j k}=\frac{c_{2}^{j k}}{\bar{c}_{2}} \quad j=S, D ; \quad k=H, T
$$

which is a strictly decreasing function of the average income of their peers.

Each individual also sees clearly their relative performance in terms of lifetime income

$$
{ }^{y} r_{2}^{j k}=\frac{y_{2}^{j k}}{\bar{y}_{2}}=\frac{c_{1}^{k}+c_{2}^{j k}}{\bar{c}_{1}+\bar{c}_{2}} \quad j=S, D ; \quad k=H, T,
$$

and this too is a strictly decreasing function of the average Period 2 income of their peers, $\bar{c}_{2}$

So, unambiguously, happiness of all individuals is a strictly decreasing function of the average Period 2 income of their peers, $\bar{c}_{2}$.

\section{Conclusion}

Though very simple, this model seems to be capable of generating predictions that are consistent with the empirical evidence; namely that, under some circumstances and for some individuals an increase in the average current income earned by their peers may make people happier early in life because of the signalling role it plays on prospects for future relative lifetime income. However, later in life, when everything has been learned, 
then, ceteris paribus, the higher the current income of their peers, the worse people think they have performed in relative terms, whether this is viewed in terms of just current performance or, looking back over one's life, in terms of lifetime performance.

\section{Endnotes}

${ }^{1}$ See, among others, Frey and Stutzer 2013; Akay and Martinsson 2012; D’Ambrosio and Frick 2012; Bartolini et al. 2012; Cuesta and Budria 2012; FitzRoy et al. 2011a, 2011b; Layard et al. 2010; Senik 2009; Clark et al. 2008; Ferrer-i-Carbonell 2005; Luttmer 2005; Blanchflower and Oswald 2004.

${ }^{2}$ In FitzRoy et al. (2011a, 2011b), while only the 2008 SOEP wave was used, it obtained many qualitatively similar results. With wave 17 of the BHPS, only an aggregate, negative significant effect of comparison was found.

${ }^{3}$ Negative comparison effects are often misleadingly described as 'envy', which does not capture preference for fairness.

${ }^{4}$ Less plausibly, Senik (2008) also finds a strong positive or signalling effect of reference income on happiness in the US, attributed to high perceived mobility, but this result is directly contradicted by Layard et al. (2010), using the same GSS data, and by Luttmer (2005) and others with various data sets.

${ }^{5} \mathrm{We}$ control for size of household and number of children.

${ }^{6}$ The issue of comparing with others at a given time rather than across the time range of a panel was examined in more detail by Mujcic and Frijters (2013), using the Household, Income and Labour Dynamics in Australia (HILDA) survey dataset.

${ }^{7}$ Comparison income was, on average, calculated on the basis of two or three hundred individual observations, essentially the most 'similar' peer group of that size. Other age splits gave similar results as already noted.

${ }^{8}$ For a detailed description, please see the Appendix.

${ }^{9}$ Technically, the earlier waves of the BHPS were limited in coverage to Great Britain. In our case, this is true up to Wave 10. The full United Kingdom (including Northern Ireland) is covered in Waves 12-18. BHPS data are available via the UK Data Service (formerly the UK Data Archive).

${ }^{10}$ Although a linear transformation can provide arithmetic equivalence, this does not negate underlying issues concerning the question of whether such scales are cardinal (with points on the scale representing equal distances in the strength of response) or simply ordinal (in which case, the mean is a problematic concept).

${ }^{11}$ We use gross household income from the BHPS due to easier availability of this measure.

${ }^{12}$ This can be confirmed by estimation for the whole sample with an interaction dummy for age $45+$.

${ }^{13}$ However, the age split for which results are shown in columns (2) and (3) cannot be simply expressed as a generalised case in column (1) - since there, under fixed effects estimation, the correlation between the two components of the disturbance term takes a particular value; whereas, in general, this correlation will take different values in each of columns (2) and (3).

${ }^{14}$ All variables except comparison income are interacted with a $45+$ dummy, but not reported. 
${ }^{15}$ The overall effect of comparison income is negative and significant at the $10 \%$ level for the under 25s but is negative overall (albeit insignificant) for the 35-44 age group.

${ }^{16}$ Results for an unreported specification with fixed effects, age group interactions and an age split on either side of the $45^{\text {th }}$ birthday show statistically significant, positive overall effects for comparison income in the younger age range (like in column (2) of Table 9).

${ }^{17}$ Results are available on request.

${ }^{18}$ A quite separate issue which has attracted much more attention is the fact that most of the gains from growth have gone to the highest earners in recent decades in Germany, UK and elsewhere. More equal Nordic countries have long had higher average life satisfaction and obviously less poverty, but without a growth trend in life satisfaction.

${ }^{19}$ ISCED denotes UNESCO's International Standard Classification of EDucation.

${ }^{20} \mathrm{We}$ could make the more general assumption that $p_{S}=\theta p_{H}, \quad 0<\theta<\frac{1}{p_{H}}$, but that adds very little to the analysis.

${ }^{21}$ Though, they were able to work this out in Period 1.

Competing interest

The IZA Journal of European Labor Studies is committed to the IZA Guiding Principles of Research Integrity. The authors declare that they have observed these principles.

\section{Acknowledgments}

Earlier versions were presented at the WPEG Conference, July 2013; Scottish Economic Society Annual Conference, Perth, April 2013; Lancaster University, November, 2012; EALE, Bonn, September 2012; the Royal Economic Society Annual Conference, Cambridge, March 2012; an Economics Seminar, St. Andrews, October 2011; a SIRE Workshop, Stirling, December 2011; and the WPEG Conference, Sheffield, July 2011. For comments and discussion, we are grateful to Danny Blanchflower, Andrew Clark, Paul Frijters, Dennis Mueller, Andrew Oswald, Alkis Otto, Peter Sloane, Alois Stutzer, Karl Taylor and seminar participants. In addition, we thank the anonymous referee for very useful comments. The authors retain responsibility. Responsible editor: Alan Barrett

\section{Author details}

${ }^{1}$ University of St Andrews, School of Economics and Finance, St. Andrews, Fife KY16, 9AR, Scotland, UK. ${ }^{2}$ University of Hull, Cottingham Road, Hull HU6 7RX, UK. 3 Helmut Schmidt University, Holstenhofweg 85, 22043 Hamburg, Germany. ${ }^{4}$ Scottish Institute for Research in Economics (SIRE), Edinburgh, Scotland, UK.

Received: 5 March 2014 Accepted: 1 October 2014

Published: 30 Dec 2014

\section{References}

Akay A, Martinsson P (2012) Positional Concerns through the Life Cycle: Evidence from Subjective Well-Being Data and Survey Experiments. Institute for the Study of Labor (IZA). IZA DP No.6342

Bartolini S, Bilancini E, Sarracino F (2012) Predicting the trend of well-being in Germany: How much do comparisons, adaptation and sociability matters? Social Indicators Research 114:169-191

Bellani L, D’Ambrosio C (2010) Deprivation, Social Exclusion and Subjective Well-Being. Social Indicators Research 104:67-86

Blanchflower DG, Oswald A (2004) Well-Being over Time in Britain and the USA. Journal of Public Economics 88:1359-1386

Blanchflower DG, Oswald A (2008) Is well-being U-shaped over the life cycle? Social Science \& Medicine 66:1733-1749

Clark AE, Frijters P, Shields MA (2008) Relative income, happiness, and utility: An explanation for the Easterlin paradox and other puzzles. Journal of Economic Literature 46:95-144

Clark AE, Kristensen N, Westergård-Nielsen N (2009) Job Satisfaction and Co-worker Wages: Status or Signal? Economic Journal 119:430-447

Clark AE, Oswald A (1996) Satisfaction and comparison income. Journal of Public Economics 61:359-381

Cuesta MB, Budria S (2012) Deprivation and subjective well-being: evidence from panel data. Review of Income and Wealth. doi:10.1111/roiw.12003

D'Ambrosio C, Frick JR (2012) Individual well-being in a dynamic perspective. Economica 79:284-302

Drichoutis AC, Nayga RM, Lazaridis P (2010) Do reference values matter? Some notes and extensions on income and happiness across Europe. Journal of Economic Psychology 31:479-486

Easterlin R (1974) Does Economic Growth Improve the Human Lot? In: David PA, Reder MW (eds) Nations and Households in Economic Growth: Essays in Honour of Moses Abramowitz. Academic Press, New York, pp 89-125

Easterlin R (2013) Happiness and Economic Growth: The Evidence. Institute for the Study of Labor (IZA). IZA DP No. 7187

Ferrer-i-Carbonell A, Frijters P (2004) How important is methodology for the estimates of the determinants of happiness. The Economic Journal 114:641-659 
Ferrer-i-Carbonell A (2005) Income and well-being: an empirical analysis of the comparison income effect. Journal of Public Economics 89:997-1019

Fischer JAV (2009) Happiness and age cycles - return to start. Munich Personal RePEc Archive. MPRA Paper No. 15249

FitzRoy F, Nolan M, Steinhardt M (2011a) Age, Life Satisfaction and Relative Income. Hamburg Institute of International Economics (HWWI). HWWI Research Paper 110

FitzRoy F, Nolan M, Steinhardt M (2011b) Age, Life-Satisfaction, and Relative Income: Insights from the UK and Germany. Institute for the Study of Labor (IZA). IZA DP No. 6045

Fliessbach K, Weber B, Trautner P, Dohmen T, Sunde U, Elger C, Falk A (2007) Social comparison affects reward-related brain activity in the human ventral striatum. Science 318:1305-1308

Frey BS, Stutzer A (eds) (2013) Recent Developments in the Economics of Happiness. Edward Elgar, Cheltenham

Frijters P, Shields MA, Haisken-DeNew JP (2004) The value of reunification in Germany; An analysis of changes in life satisfaction? Journal of Human Resources 3:649-674

Frijters P, Beatton T (2012) The mystery of the U-shaped relationship between happiness and age. Journal of Economic Behavior and Organization 82:525-542

Headey B, Muffels R, Wagner G (2012) Parents Transmit Happiness along with Associated Values and Behaviors to Their Children: A Lifelong Happiness Dividend? Institute for the Study of Labor (IZA). IZA DP No. 6944

Helliwell J, Layard R, Sachs J (2012) World Happiness Report. Columbia University, Earth Institute

Hirschman AO, Rothschild M (1973) The Changing Tolerance for Income Inequality in the Course of Economic Development. The Quarterly Journal of Economics 87:544-566

Kassenboehmer S, Haisken-DeNew JP (2012) Heresy or enlightenment? The well-being age U-shape effect is flat. Economics Letters 117:235-238

Layard R, Mayraz G, Nickell S (2010) Does Relative Income Matter? Are the Critics Right? In: Diener E, Helliwell JF, Kahneman D (eds) International Differences in Well-being. Oxford University Press

Layard R, Clark AE, Cornaglia F, Poudthavee N, Vernoit J (2013) What Predicts a Successful Life? A Life-Course Model of Well-Being. Institute for the Study of Labor (IZA). IZA DP No. 7682

Luttmer RFP (2005) Neighbors as Negatives: Relative Earnings and Well-Being. Quarterly Journal of Economics 30:963-1002

McBride M (2001) Relative-income effects on subjective well-being in the cross-section. Journal of Economic Behavior \& Organization 45:251-278

Moulton BR (1990) An Illustration of a Pitfall in Estimating the Effects of Aggregate Variables on Micro Units. Review of Economics and Statistics 72:334-338

Mujcic R, Frijters P (2013) Conspicuous Consumption, Conspicuous Health, and Optimal Taxation. School of Economics, University of Queensland, Discussion Paper Series No 483

Pfaff T, Hirata J (2011) Can Germans hope that economic growth will make them happier one day? An analysis of the Easterlin Hypothesis using German panel data. University of Muenster, mimeo

Pfaff T (2013) Income Comparisons, Income Adaptation, and Life Satisfaction: How Robust Are Estimates from Survey Data. German Institute for Economic Research (DIM). SOEP Papers 555

Runciman WG (1966) Relative Deprivation and Social Justice. Routledge and Kegan Paul, London

Senik C (2004) When Information Dominates Comparison: Learning from Russian Subjective Panel Data. Journal of Public Economics 88:2099-2133

Senik C (2008) Ambition and Jealousy: Income Interactions in the 'Old' Europe versus the 'New' Europe and the United States. Economica 75:495-513

Senik C (2009) Direct Evidence on Income Comparisons and their Welfare Effects. Journal of Economic Behavior and Organization 72:408-424

Veblen T (1899) The Theory of the Leisure Class. Macmillan Company, New York

Wagner GG, Frick JR, Schupp J (2007) The German Socio-Economic Panel Study (SOEP) - Scope, Evolution and Enhancements. Schmollers Jahrbuch 127:139-169

Wunder C, Wiencierz A, Schwarze J, Küchenhoff H (2013) Well-being over the lifespan: Semiparametric evidence from British and German longitudinal data. Review of Economics and Statistics 95:154-167

10.1186/2193-9012-3-24

Cite this article as: FitzRoy et al:: Testing the tunnel effect: comparison, age and happiness in UK and German panels. IZA Journal of European Labor Studies 2014, 3:24

\section{Submit your manuscript to a SpringerOpen ${ }^{\circ}$ journal and benefit from:}

- Convenient online submission

- Rigorous peer review

- Immediate publication on acceptance

- Open access: articles freely available online

- High visibility within the field

Retaining the copyright to your article

Submit your next manuscript at $\boldsymbol{\sim}$ springeropen.com 